RODRIGUES, B.H.N. et al. Produção e composição bromatológica do capim-Tanzânia (Panicum maximum) em diferentes idades de rebrotação. PUBVET, Londrina, V. 8, N. 8, Ed. 257, Art. 1700, Abril, 2014.

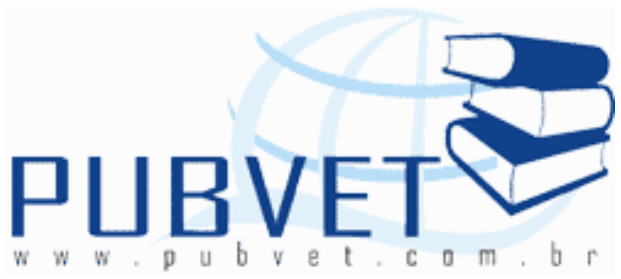

PUBVET, Publicações em Medicina Veterinária e Zootecnia.

\title{
Produção e composição bromatológica do capim-Tanzânia (Panicum maximum) em diferentes idades de rebrotação
}

\author{
Braz Henrique Nunes Rodrigues ${ }^{1}$, Alex Carvalho Andrade ${ }^{2}$, João Avelar \\ Magalhães ${ }^{3}$, Pedro Dantas Fernandes ${ }^{4}$, Francisco José de Seixas Santos ${ }^{5}$, \\ Newton de Lucena Costa ${ }^{6}$
}

${ }^{1}$ Eng. Agrícola, D.Sc., Pesquisador da Embrapa Meio-Norte, Parnaíba, PI.

${ }^{2}$ Zootec., D.Sc., Professor Universidade Estadual do Piauí, Parnaíba, PI.

${ }^{3}$ Méd. Vet., D.Sc., Pesquisador da Embrapa Meio-Norte, Parnaíba, PI.

${ }^{4}$ Eng. Agr., D.Sc,. Pesquisador do INSA, Campina Grande, PB.

${ }^{5}$ Eng. Agr., D.Sc., Pesquisador da Embrapa Meio-Norte, Parnaíba, PI.

${ }^{6}$ Eng. Agr., D.Sc., Pesquisador da Embrapa Roraima, Boa Vista, RR.

\section{Resumo}

Avaliou-se o efeito de diferentes idades de rebrotação sobre a produção e o valor nutritivo do capim-Tanzânia nas condições ecológicas dos tabuleiros costeiros do Piauí. O delineamento experimental utilizado foi blocos ao acaso, com cinco repetições, sendo os tratamentos constituídos por cinco idades de rebrotação $(7,14,21,28$ e 35 dias), perfazendo um total de vinte e cinco parcelas ou unidades experimentais de $6 \mathrm{~m}^{2}$ cada uma. As avaliações compreenderam dois períodos experimentais, sendo o primeiro de 02/09/2008 a 16/12/2008 e o segundo de 01/09/2009 a 15/12/2009. Nos dois períodos a produção de matéria seca e a composição bromatológica foram avaliadas após três cortes de uniformização, a $10 \mathrm{~cm}$ do solo, a cada 35 dias, nas cinco idades 
RODRIGUES, B.H.N. et al. Produção e composição bromatológica do capim-Tanzânia (Panicum maximum) em diferentes idades de rebrotação. PUBVET, Londrina, V. 8, N. 8, Ed. 257, Art. 1700, Abril, 2014.

de rebrotação. A área experimental recebeu, parceladamente, a adubação de $340 \mathrm{~kg} \mathrm{ha}^{-1}$ de $\mathrm{N}$ e $252 \mathrm{~kg} \mathrm{ha}^{-1}$ de $\mathrm{K}_{2} \mathrm{O}$ no primeiro ano e $420 \mathrm{~kg} \mathrm{ha}^{-1}$ de $\mathrm{N}$ e $336 \mathrm{~kg} \mathrm{ha}^{-1}$ de $\mathrm{K}_{2} \mathrm{O}$ no segundo ano, além de $70 \mathrm{~kg} \mathrm{ha}^{-1}$ de $\mathrm{P}_{2} \mathrm{O}_{5}$ na fundação. As irrigações foram realizadas através de um sistema de aspersão convencional fixo, de baixa pressão e vazão. A produtividade de matéria seca aumentou linearmente com a idade de rebrotação atingindo o valor de $5,7 \mathrm{t}$ $\mathrm{ha}^{-1}$ aos 35 dias. $\mathrm{O}$ teor de matéria seca (TMS) aumentou linearmente com a idade de rebrotação, variando de $15,64 \%$ a $20,14 \%$ dos 7 aos 35 dias. O teor de proteína bruta (PB) apresentou comportamento inverso, reduzindo-se linearmente de 17,0 a $7,8 \%$ dos 07 aos 35 dias. $O$ teor de fibra em detergente neutro (FDN) também apresentou resposta linear, atingindo o limite crítico inferior a $60 \%$ de 24 a 28 dias de rebrota e o teor de fibra em detergente ácido (FDA), através de um comportamento quadrático estimou valores próximos a $35 \%$ até a idade de 28 dias. Considerando, em conjunto, os limites críticos para valores de PB, FDN e FDA, bem como um valor adequado para TMS, recomenda-se para o capim-Tanzânia, nas condições ecológicas dos tabuleiros costeiros do Piauí, um período de descanso entre 21 e 28 dias.

Termos para indexação: FDA, FDN, manejo de pastagem, proteína bruta.

\title{
Production and bromatologic composition of Tanzania grass (Panicum maximum) at different regrowth ages
}

\begin{abstract}
The effect of different regrowth ages on the production and nutritional value of grass Tanzania were evaluated in ecological conditions of the coastal plains of Piauí. The experimental design was a randomized complete block with five replications, with treatments consisting of five ages of regrowth $(7,14,21,28$ and 35 days), making a total of twenty-five plots or experimental units of $6 \mathrm{~m}^{2}$ each. The evaluations were two experimental periods, the first of 02/09/2008 to $16 / 12 / 2008$ and the second from $01 / 09 / 2009$ to $15 / 12 / 2009$. In both
\end{abstract}


RODRIGUES, B.H.N. et al. Produção e composição bromatológica do capim-Tanzânia (Panicum maximum) em diferentes idades de rebrotação. PUBVET, Londrina, V. 8, N. 8, Ed. 257, Art. 1700, Abril, 2014.

periods the nutritional values were evaluated in three cuts, $10 \mathrm{~cm}$ of soil, with an interval of 35 days, in the five ages of regrowth. The experimental area received the fertilization of $340 \mathrm{~kg} \mathrm{ha}^{-1} \mathrm{~N}$ and $252 \mathrm{~kg} \mathrm{~K}_{2} \mathrm{O}$ ha ${ }^{-1}$ in the first year and $420 \mathrm{~kg} \mathrm{ha}^{-1} \mathrm{~N}$ and $336 \mathrm{~kg} \mathrm{~K}_{2} \mathrm{O} \mathrm{ha}{ }^{-1}$ in the second year, plus $70 \mathrm{~kg} \mathrm{ha}^{-1}$ $\mathrm{P}_{2} \mathrm{O}_{5}$ in the foundation. Irrigation was applied through a sprinkler system, low pressure and low flow. The dry matter yield increased proportionally with age of regrowth reached a value of $5.7 \mathrm{t} \mathrm{ha}^{-1}$ in 35 days. The dry matter content increases with age of regrowth, ranging from $15.64 \%$ to $20.14 \%$ from 7 to 35 days. The crude protein content showed an opposite behavior, decreasing linearly from 17.0 to $7.8 \%$ from 7 to 35 days. The neutral detergent fiber content also linearly, reaching the critical limit of less than $60 \%$ from 24 to 28 days of regrowth and the acid detergent fiber content, using a quadratic behavior estimated values close to $35 \%$ by the age of 28 days. Considering together the critical limits for crude protein, neutral detergent fiber and acid detergent fiber, and an appropriate value for the dry matter content is recommended for the grass-Tanzania, in the ecological conditions of the coastal plains of Piauí, observe a rest period between 21 and 28 days.

Index terms: Acid detergent fiber, crude protein, grassland management, neutral detergent fiber.

\section{Introdução}

Na produção de bovinos a pasto, a quantidade de forragem produzida é importante, porém, incrementos na produção de forragem não implicam, necessariamente, em aumento no desempenho animal. Quando o objetivo é aumentar a quantidade de produto por área (carne ou leite) deve-se ter como propósito aumentar a quantidade de forragem, sem comprometer a sua qualidade.

A produção e a qualidade da biomassa de uma espécie forrageira são conseqüências da transformação de energia solar e $\mathrm{CO}_{2}$ atmosférico em compostos orgânicos, condicionada por fatores climáticos, como: temperatura, luminosidade, pluviosidade (influenciando na umidade do solo), fatores ligados 
RODRIGUES, B.H.N. et al. Produção e composição bromatológica do capim-Tanzânia (Panicum maximum) em diferentes idades de rebrotação. PUBVET, Londrina, V. 8, N. 8, Ed. 257, Art. 1700, Abril, 2014.

à planta, ao solo (disponibilidade de nutrientes), a presença do animal e as interações que ocorrem entre estes fatores. Uma vez definida a espécie forrageira e corrigida a fertilidade do solo, a qualidade forrageira ao longo do ano será definida, principalmente, pelo estádio de crescimento e pelas condições climáticas locais (RIBEIRO, 2004).

A determinação da composição bromatológica das frações que compõem a planta forrageira é de fundamental importância para a previsão do desempenho animal em sistemas de produção, pois permite estimar o seu valor nutritivo (GERDES et al., 2000; BALSALOBRE, 2002).

O conceito de "valor nutritivo" refere-se à composição química da forragem e sua digestibilidade, enquanto a eficiência da utilização das plantas forrageiras pelos animais está na dependência da qualidade e da quantidade de forragem disponível na pastagem, e do potencial do animal. A qualidade de uma planta forrageira corresponde a sua capacidade em gerar desempenho animal, ou seja, à associação entre sua composição química, digestibilidade, consumo voluntário e interação de fatores hereditários e ambientais (CASTAGNARA, 2009). O solo, o clima, e as doenças influenciam o crescimento e a composição das plantas forrageiras (VAN SOEST, 1994), enquanto fatores como idade, altura de corte ou pastejo, adubação e características morfológicas da planta determinam o seu valor nutritivo (ABRAHÃO, 1996). Segundo Euclides et al. (2001), a constituição genética da planta define seu potencial produtivo, no entanto, o manejo é o responsável pela sua expressão.

A quantidade e a qualidade da forragem produzida são características antagônicas, isto é, à medida que se aumenta o intervalo de cortes, beneficiase a produção de quantidade de forragem, mas em prejuízo de sua qualidade (LACERDA et al., 2009). A qualidade envolve todos os atributos físicos e químicos da forragem, afetando a taxa de consumo diretamente via seletividade do pastejo e indiretamente via taxa de processamento do alimento no trato digestivo do animal (PENA, 2007).

O estádio de desenvolvimento da planta também apresenta ampla relação com a composição química e a qualidade das forrageiras. Com o 
RODRIGUES, B.H.N. et al. Produção e composição bromatológica do capim-Tanzânia (Panicum maximum) em diferentes idades de rebrotação. PUBVET, Londrina, V. 8, N. 8, Ed. 257, Art. 1700, Abril, 2014.

crescimento das forrageiras, ocorrem aumentos nos teores de carboidratos estruturais e lignina, o que proporciona redução na digestibilidade, alteração nas estruturas das plantas mais velhas, apresentando maiores proporções de talos que de folhas, tendo, portanto, reduzido o seu conteúdo em nutrientes, potencialmente digeríveis com a maturação (CEDEÑO et al., 2003, EUCLIDES et al., 2001).

Das frações estudadas na composição química das plantas, as frações, fibrosa e protéica, são as mais comumente analisadas, pois seus teores podem ser afetados por diversos fatores, entre eles, a espécie ou cultivar, a fertilidade do solo e a idade da planta (VAN SOEST, 1994). O estudo dos teores de proteína (PB), das fibras em detergente neutro (FDN) e em detergente ácido (FDA) é fundamental na análise qualitativa de gramíneas, pois esses parâmetros podem influenciar direta ou indiretamente o consumo de matéria seca (MS) pelo animal (CASTAGNARA, 2009). A FDA está mais correlacionada com a digestibilidade do que com a ingestão, ocorrendo o inverso com a proteína e a FDN (VAN SOEST, 1994).

Tendo em vista a grande variação das condições ecológicas das regiões produtivas do Brasil, a variabilidade genética das espécies forrageiras disponíveis e a busca por forrageiras cada vez mais adaptadas, produtivas e de boa qualidade, é de suma importância a avaliação da composição químicobromatológica, principalmente os teores de MS, PB, FDN e FDA em diferentes idades de corte, permitindo não só a comparação entre diferentes espécies, mas também, o estudo do melhor estádio de maturação para estabelecimento de manejo e utilização das plantas (RODRIGUES et al., 2004; MAGALHÃES, 2010).

Com base nessa afirmação, objetivou-se com este trabalho avaliar o efeito de diferentes idades de rebrotação sobre a produção e os teores de matéria seca, proteína bruta, fibra em detergente neutro e fibra em detergente ácido no capim-Tanzânia (Panicum maximum cv. Tanzânia) nas condições ecológicas dos tabuleiros costeiros do Piauí. 
RODRIGUES, B.H.N. et al. Produção e composição bromatológica do capim-Tanzânia (Panicum maximum) em diferentes idades de rebrotação. PUBVET, Londrina, V. 8, N. 8, Ed. 257, Art. 1700, Abril, 2014.

\section{Material e Métodos}

O trabalho foi conduzido na área experimental da Embrapa Meio-Norte, em Parnaíba, Piauí (latitude de $3^{\circ} 5^{\prime}$ Sul, longitude de $41^{\circ} 47^{\prime}$ Oeste e altitude de $46,8 \mathrm{~m}$ ), durante dois anos consecutivos (2008 e 2009) no período de setembro a dezembro.

O clima do Município de Parnaíba, conforme a classificação climática de Thornthwaite e Mather, é $\mathrm{C}_{1} \mathrm{dA}^{\prime} \mathrm{a}^{\prime}$, caracterizado como subúmido seco, megatérmico, com pequeno excedente hídrico e uma concentração de 32,6\% da evapotranspiração potencial no último trimestre do ano (ANDRADE JÚNIOR et al., 2005). A precipitação média anual está em torno de $1.079 \mathrm{~mm}$ e período chuvoso de janeiro a junho, com evapotranspiração de referência média anual por Penman-Monteith de $1.862 \mathrm{~mm}$. A temperatura média anual é de $27^{\circ} \mathrm{C}$, umidade relativa média de $76,5 \%$ e insolação média de $8,0 \mathrm{~h} \mathrm{dia}^{-1}$. A velocidade do vento é, em média, 2-5 $\mathrm{m} \mathrm{s}^{-1}$, com direção predominante de $\mathrm{NE}$ e E (BASTOS et al., 2006).

O solo da área experimental foi classificado como Latossolo Amarelo distrófico, textura média, fase caatinga litorânea de relevo plano e suave ondulado (MELO et al., 2004). O capim-Tanzânia (Panicum maximum Jacq, cv. Tanzânia) foi implantado durante o período chuvoso de 2008 (21/05/2008), recebendo como adubação de fundação $70 \mathrm{~kg} \mathrm{ha}^{-1}$ de $\mathrm{P}_{2} \mathrm{O}_{5}$ na forma de superfosfato simples. As adubações iniciais de nitrogênio e potássio foram de $100 \mathrm{~kg} \mathrm{ha}^{-1}$ de $\mathrm{N}$ e $60 \mathrm{~kg} \mathrm{ha}^{-1}$ de $\mathrm{K}_{2} \mathrm{O}$, nas formas de ureia e cloreto de potássio, respectivamente, fracionadas em duas etapas aos 30 e 45 dias do plantio. A gramínea, após o seu estabelecimento definitivo, recebeu adubações de nitrogênio e potássio após os cortes de uniformização, que foram realizados a cada 35 dias, na dosagem de $60 \mathrm{~kg} \mathrm{ha}^{-1}$ de $\mathrm{N}$ e $48 \mathrm{~kg} \mathrm{ha}^{-1}$ de $\mathrm{K}_{2} \mathrm{O}$, perfazendo ao final do primeiro ano (2008) o equivalente a $340 \mathrm{~kg} \mathrm{ha}^{-1}$ de N e $252 \mathrm{~kg} \mathrm{ha}^{-1}$ de $\mathrm{K}_{2} \mathrm{O}$. No segundo ano (2009) foram aplicados o total de $420 \mathrm{~kg}$ ha ${ }^{-1}$ de $\mathrm{N}$ e $336 \mathrm{~kg} \mathrm{ha}^{-1}$ de $\mathrm{K}_{2} \mathrm{O}$, fracionados após cada corte de uniformização realizado. No segundo ano (2009), foram também aplicados $70 \mathrm{~kg} \mathrm{ha}^{-1}$ de $\mathrm{P}_{2} \mathrm{O}_{5}$ 
RODRIGUES, B.H.N. et al. Produção e composição bromatológica do capim-Tanzânia (Panicum maximum) em diferentes idades de rebrotação. PUBVET, Londrina, V. 8, N. 8, Ed. 257, Art. 1700, Abril, 2014.

no corte imediatamente anterior ao primeiro corte de uniformização da coleta de dados do período.

As irrigações foram realizadas através de um sistema de aspersão convencional fixo, de baixa pressão e vazão, com espaçamento entre linhas laterais e entre aspersores de $12 \mathrm{~m} \times 12 \mathrm{~m}$, utilizando-se aspersores com vazão de $0,630 \mathrm{~m}^{3} \mathrm{~h}^{-1}$. As aplicações de água foram feitas a cada dois dias, quando então era reposta a evapotranspiração da cultura (ETc) medida e registrada no intervalo, em uma bateria de lisímetros, anexa à área do experimento. No primeiro ano (2008) foram aplicados 256,11 mm, 271,58 mm e 252,61 mm durante o período de 35 dias compreendido pelos cortes 1, 2 e 3, respectivamente. No segundo ano (2009) as aplicações foram de 264,52 mm, $287,51 \mathrm{~mm}$ e $256,32 \mathrm{~mm}$ para o período de 35 dias do primeiro, segundo e terceiro cortes, respectivamente.

O delineamento utilizado foi o de blocos ao acaso, com cinco repetições, sendo os tratamentos constituídos por cinco idades de rebrotação $(7,14,21$, 28 e 35 dias), perfazendo um total de vinte e cinco parcelas ou unidades experimentais de $6 \mathrm{~m}^{2}(3 \times 2 \mathrm{~m})$ cada uma. As avaliações compreenderam dois períodos experimentais, sendo o primeiro de 02/09/2008 a 16/12/2008 e o segundo de 01/09/2009 a 15/12/2009. Nos dois períodos os valores nutritivos foram avaliados após três cortes de uniformização, a $10 \mathrm{~cm}$ do solo, a cada 35 dias, nas cinco idades de rebrotação (7, 14, 21, 28 e 35 dias).

Nas datas estabelecidas, para cada idade de rebrota, o material usado para estimativa da produção e dos valores nutritivos foi colhido em uma área útil de $1,0 \mathrm{~m}^{2}$, estabelecida por um quadrado de $1,0 \mathrm{~m}$ de lado. Dentro desse quadrado de $1,0 \mathrm{~m}^{2}$ foi lançado outro quadrado de $0,25 \mathrm{~m}^{2}$, cujo material foi utilizado para determinação das frações lâmina foliar e colmo + bainha e, quando presente, material morto. O material foi cortado, ao nível do solo, com o auxílio de um "cutelo" e acondicionado em sacos plásticos, que foram imediatamente levados ao laboratório para pesagem e estimativa da massa verde da área útil. A lâmina foliar + (colmo + bainha) foi tratada como folha + colmo. 
RODRIGUES, B.H.N. et al. Produção e composição bromatológica do capim-Tanzânia (Panicum maximum) em diferentes idades de rebrotação. PUBVET, Londrina, V. 8, N. 8, Ed. 257, Art. 1700, Abril, 2014.

No laboratório foram separadas as frações folha e colmo em uma amostra representativa do material colhido no quadrado de $0,25 \mathrm{~m}^{2}$, além de uma amostra composta de folha + colmo que, posteriormente foram levadas para secagem em estufa a $65^{\circ} \mathrm{C}$ por 72 horas até peso constante. Após secagem, as amostras individuais de folha e colmo foram pesadas para determinação da produtividade de matéria seca (PRODMS), do teor de matéria seca (TMS), e as amostras compostas de folha + colmo foram pesadas e separadas para posterior moagem em moinho tipo "Willey", com peneira de 30 "mesh". Em seguida, elas foram acondicionadas em sacos plásticos, vedadas e encaminhadas aos Laboratórios de Bromatologia da Embrapa Meio-Norte e UFPI em Teresina, para determinação dos teores de proteína bruta e fibras em detergente neutro e ácido, respectivamente.

A composição bromatológica foi determinada quanto aos teores de proteína bruta (PB), pelo método de Kjeldahl, como descrito por Silva e Queiroz (2002) e fibra em detergente neutro (FDN) e fibra em detergente ácido (FDA), segundo método de Van Soest, adaptado por Souza et al. (1999).

Os valores médios de PRODMS, TMS, PB, FDN e FDA, em função da idade de rebrotação, foram interpretados por meio de análise de regressão. A escolha do modelo foi feita com base no coeficiente de determinação $\left(R^{2}\right)$, na significância da regressão e de seus coeficientes, e pela lógica biológica da variável em estudo.

\section{Resultados e discussão}

A produtividade de matéria seca (PRODMS) aumentou linearmente $(p<0,01)$ com a idade de rebrotação (Figura 1), com incrementos de 0,15 t por dia de rebrotação, atingindo o valor máximo de $5,7 \mathrm{t} \mathrm{ha}^{-1}$ aos 35 dias.

Em condições edafoclimáticas semelhantes, Rodrigues et al. (2006) também obtiveram comportamento linear crescente da PRODMS em capimTanzânia cortado aos 28, 56 e 84 dias, em que aos 28 dias a PRODMS foi de 4,09 $\mathrm{t} \mathrm{ha}^{-1}$, coerente com o valor de 5,7 t ha-1 obtido neste trabalho, aos 35 dias de rebrotação. Esses resultados são similares ainda aos obtidos por 
RODRIGUES, B.H.N. et al. Produção e composição bromatológica do capim-Tanzânia (Panicum maximum) em diferentes idades de rebrotação. PUBVET, Londrina, V. 8, N. 8, Ed. 257, Art. 1700, Abril, 2014.

Rodrigues et al. (2005), cuja produtividade média por corte do capim-Tanzânia aos 28 dias foi de 4,99 $\mathrm{t} \mathrm{ha}^{-1}$. Benedetti et al. (2001) obtiveram produtividade de matéria seca do capim-Tanzânia irrigado variando de 2,9 a 6,4 t ha-1 em idades de corte aos 30 e 75 dias, respectivamente, nas condições do Cerrado de Minas Gerais. A explicação para os valores mais baixos obtidos por esses autores deve-se, possivelmente, às condições de temperatura mínima e período luminoso crítico em relação ao crescimento de forrageiras tropicais, verificados durante a condução do experimento naquela região.

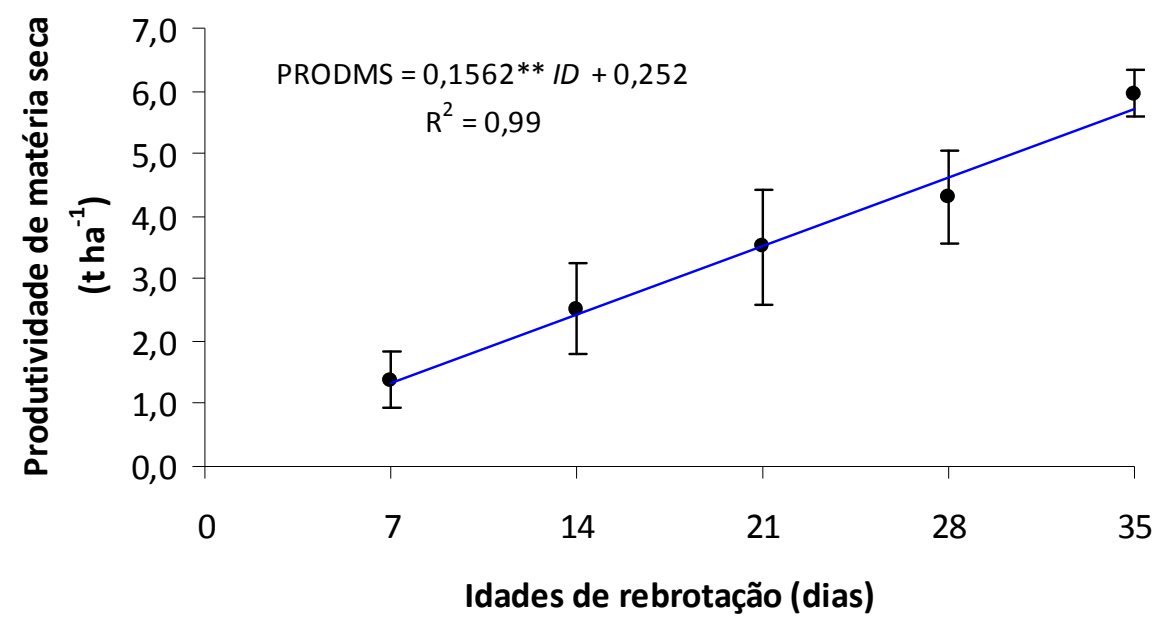

Figura 1. Valores médios observados e estimativa das produtividades de matéria seca (PRODMS) do Panicum maximum cv. Tanzânia em diferentes idades de rebrotação, em Parnaíba, Piauí. As barras indicam os desviospadrão.

A adequada disponibilidade de água (média de $265 \mathrm{~mm}$ durante os 35 dias) e nitrogênio ( $420 \mathrm{~kg} \mathrm{ha}^{-1} \mathrm{ano}^{-1}$ ) utilizada neste experimento justifica os valores de PRODMS encontrados. A adubação nitrogenada tem efeito direto sobre a área foliar fotossintetizante, como consequência do incremento na taxa de alongamento foliar, uma evidência da importância do nutriente $\mathrm{N}$ para o acréscimo na produção de forragem. Além dessa influência, o $\mathrm{N}$ atua como 
RODRIGUES, B.H.N. et al. Produção e composição bromatológica do capim-Tanzânia (Panicum maximum) em diferentes idades de rebrotação. PUBVET, Londrina, V. 8, N. 8, Ed. 257, Art. 1700, Abril, 2014.

fator controlador dos diferentes processos de crescimento e desenvolvimento das plantas, proporcionando aumento de biomassa pela fixação de carbono (MAGALHÃES, 2007). Os resultados obtidos corroboram ainda aos descritos por Martuscello et al. (2004), Garcez Neto et al. (2002) e Alexandrino et al. (2003) sobre o efeito de $\mathrm{N}$ sobre a produção de matéria seca.

$O$ teor de matéria seca (TMS) aumentou linearmente $(P<0,01)$ com a idade de rebrotação, com incrementos de 0,16 \% por dia de rebrotação, estimando-se valores de 15,64 e 20,14\%, aos 07 e 35 dias, respectivamente (Figura 2). A planta, quando nova, apresenta altos teores de água, no entanto quanto mais próximo da sua maturidade esse teor é reduzido e ocorre um aumento nos teores de matéria seca. De acordo com Costa et al. (2007) à medida que prolonga o intervalo de cortes, o teor de matéria seca da forragem tende a aumentar. Os resultados encontrados se aproximam daqueles obtidos com o capim-Tanzânia e o capim-Mombaça por diversos autores (RODRIGUES et al., 2006; PALIERAQUI et al., 2006; TINOCO et al., 2008).

Ribeiro et al. (2004), analisando o capim-Mombaça cortado aos 35 dias encontraram valores de TMS de 20 e 23,5\% com e sem irrigação, respectivamente. Considerando o adequado aporte de água neste trabalho, com aplicação média de $264 \mathrm{~mm}$ de água no intervalo de 35 dias, o valor de $20 \%$ encontrado por aqueles autores na condição irrigada, equivale fielmente ao valor encontrado neste trabalho. Gerdes et al. (2000) trabalhando com os capins Marandu, Setária e Tanzânia aos 35 dias de crescimento, nas quatro estações do ano, encontraram para o capim-Tanzânia valores de TMS de $19,35 \%$ na primavera, $19,50 \%$ no verão, $16,94 \%$ no outono e $22,92 \%$ no inverno. Estes resultados também se aproximam dos encontrados neste trabalho e corroboram com as afirmações de Magalhães (2010) de que nos tratamentos onde ocorre maior aplicação de água, os teores de matéria seca tendem a serem menores, em razão da maior disponibilidade de água a ser absorvida do solo e, consequentemente, maiores teores de água nas células, resultando em menores teores de matéria seca. Euclides (1995), entre outros autores, mencionam que baixos teores de matéria seca em gramíneas 
RODRIGUES, B.H.N. et al. Produção e composição bromatológica do capim-Tanzânia (Panicum maximum) em diferentes idades de rebrotação. PUBVET, Londrina, V. 8, N. 8, Ed. 257, Art. 1700, Abril, 2014.

forrageiras são um dos fatores que limitam o consumo das mesmas pelos animais. Trabalhando com o capim-buffel, Dantas Neto et al. (2000) reportaram que os teores de matéria seca foram reduzidos de 44,03\% para 27,56\%, quando aumentou a lâmina de $118 \mathrm{~mm}$ para $470 \mathrm{~mm}$.

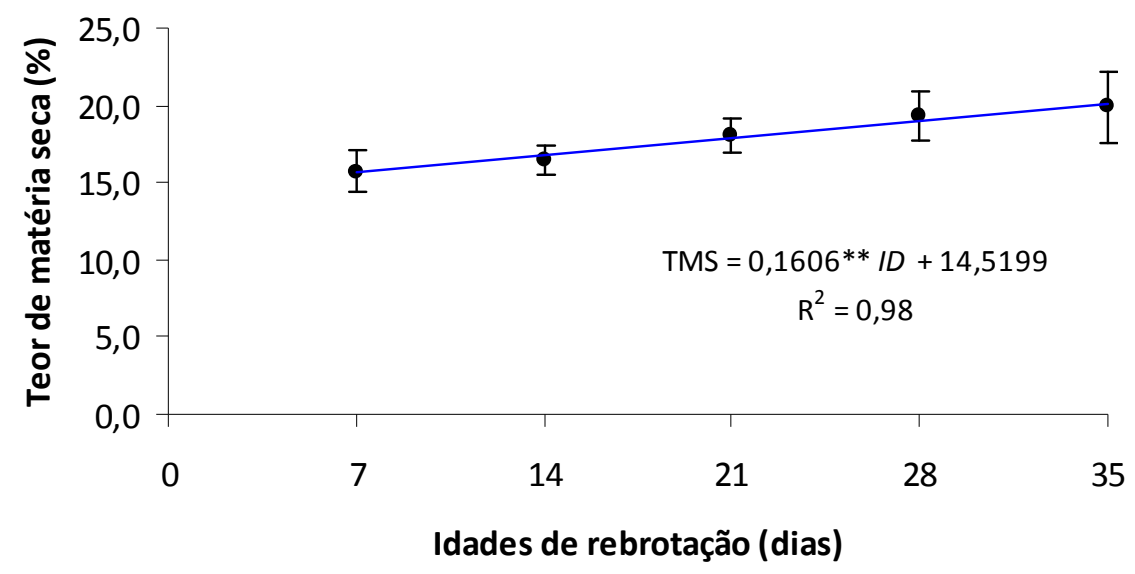

Figura 2. Valores médios observados e estimativa dos teores de matéria seca do Panicum maximum cv. Tanzânia em diferentes idades de rebrotação, em Parnaíba, Piauí. As barras indicam os desvios-padrão.

Assim como para o TMS, o conteúdo de proteína bruta (PB) apresentou um comportamento linear com a idade de rebrotação $(P<0,01)$, todavia a relação foi inversa, ou seja, houve uma redução de $0,33 \%$ nos valores de PB para cada dia de rebrotação da gramínea (Figura 3). Os valores variaram de 17,0 a $7,8 \%$ para 7 e 35 dias, respectivamente.

A redução de PB com o avanço da maturidade das plantas é um fato amplamente relatado na literatura (AGUIAR et al., 2000; FRANÇA et al., 2007; COSTA et al., 2007; VERDECIA et al., 2008; SILVA, 2009), e deve-se, provavelmente ao efeito de diluição do conteúdo de $\mathrm{PB}$ na matéria seca produzida e acumulada (ANDRADE et al., 2003).

Resultados semelhantes também foram obtidos por Borges et al. (2002) quando trabalhavam com capim-Marandu. $O$ intervalo de corte indicou 
RODRIGUES, B.H.N. et al. Produção e composição bromatológica do capim-Tanzânia (Panicum maximum) em diferentes idades de rebrotação. PUBVET, Londrina, V. 8, N. 8, Ed. 257, Art. 1700, Abril, 2014.

comportamento diferente para PB, causando uma diminuição com o aumento de 60 dias de crescimento. Os maiores teores de PB foram verificados no intervalo de corte de 15 e 20 dias, chegando a atingir 16,02\%, diferenciando estatisticamente $(P<0,01)$ do intervalo de 30 e 60 dias. Os elevados teores observados para PB nos tratamentos onde a forragem é colhida em estádio vegetativo inicial, provavelmente, devem-se às elevadas percentagens de folhas e baixas percentagens de colmos. Segundo El-Memari Neto et al. (2002) as folhas são notadamente mais digestíveis e nutricionalmente mais ricas. Castro et al. (2004) trabalhando com Brachiaria brizantha cv. Marandu com idade de corte de $28,56,84$ e 112 dias, também verificaram que os valores de PB diminuíram com o aumento da idade de corte. Balsalobre et al. (2001) relatam que as maiores mudanças que ocorrem na composição das plantas forrageiras são aquelas decorrentes de sua maturidade. A maioria das espécies forrageiras sofre declínio no seu valor nutritivo com o aumento da idade, quando o conteúdo celular diminui, resultante da crescente lignificação da parede celular (AGUIAR et al., 2000; COSTA et al., 2007).

Segundo Verdecia et al., (2008) uma maior idade da planta e decrescendo a quantidade de folhas, aumenta a síntese de carboidratos estruturais (celulose, hemicelulose e lignina) e consequentemente diminui a qualidade da pastagem.

Neste trabalho, os teores estimados de PB estiveram acima dos 7\%, em todas as idades de crescimento (inclusive aos 35 dias), considerado como o mínimo exigido para o atendimento das necessidades nutricionais dos ruminantes (MINSON e WILSON, 1994). Segundo NRC (1984) este limite de $7 \%$ se aplica a bovinos adultos, aumentando-se para $11 \%$ a exigência mínima de PB quando se trata de animais jovens. Os autores afirmam que teores de PB abaixo dos limites críticos ocasionam queda na ingestão de matéria seca pelos animais, devido à carência de nitrogênio aos microorganismos ruminais. Neste trabalho o nível mínimo de $11 \%$ foi atingido aos $24-25$ dias de rebrotação. 
RODRIGUES, B.H.N. et al. Produção e composição bromatológica do capim-Tanzânia (Panicum maximum) em diferentes idades de rebrotação. PUBVET, Londrina, V. 8, N. 8, Ed. 257, Art. 1700, Abril, 2014.

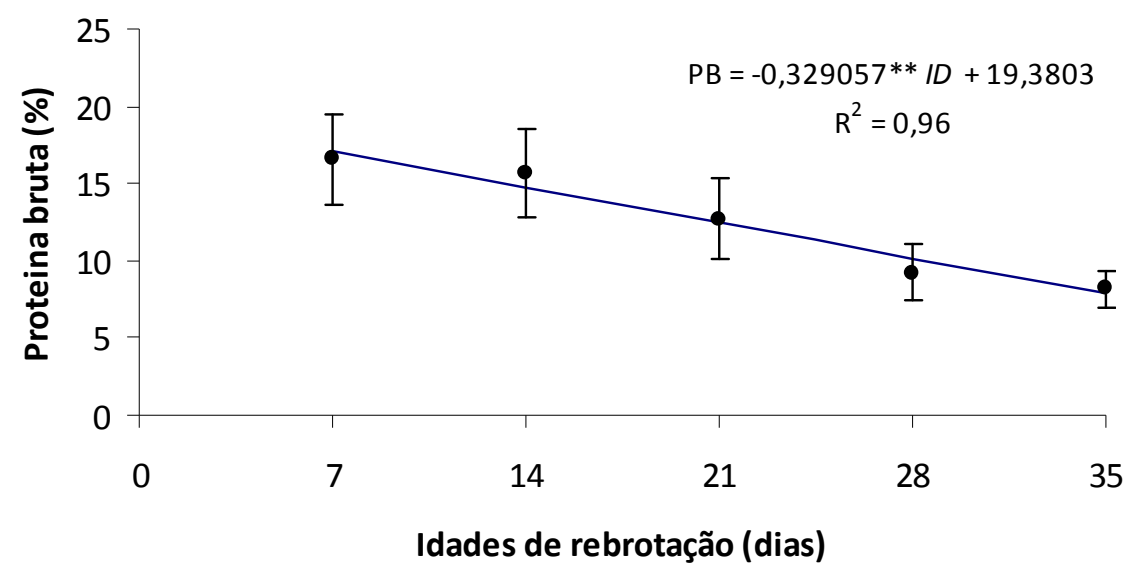

Figura 3. Valores médios observados e estimativa dos teores de proteína bruta do Panicum maximum cv. Tanzânia em diferentes idades de rebrotação, em Parnaíba, Piauí. As barras indicam os desvios-padrão.

Souza et al. (2006) trabalhando com três cultivares de Panicum maximum Jacq. obtiveram teores médios de PB de 12,7\%, 15,3\% e 14,0\% para os capins Massai, Atlas e Tobiatã, respectivamente, que podem ser considerados satisfatórios para cultivares desse gênero, uma vez que se encontram acima de 12\% (CECATO et al, 2001). Os teores médios de PB no Atlas e Tobiatã foram superiores ao valor médio encontrado por Balsalobre et al (2003) para o capim-Tanzânia, equivalente a 12,9\%, manejado sob ciclo de pastejo de 36 dias, valor superior ao encontrado neste trabalho.

$\mathrm{Na}$ literatura é muito relatada a relação dos níveis de adubação nitrogenada com o conteúdo de PB das forragens. Oliveira (2002) avaliando o rendimento e o valor nutritivo do capim-coastcross sob diferentes doses de nitrogênio e idades de rebrota, observou interação entre $\mathrm{N}$ e idade de rebrota para os teores de PB na planta. Segundo o autor, sob baixas doses de N, o efeito da idade de rebrota praticamente desaparece, provavelmente em função dos altos valores de relação folha:colmo nessa condição.

França et al. (2007) avaliando o efeito de 3 doses de N (200, 400 e 600 $\left.\mathrm{kg} \mathrm{ha}^{-1} \mathrm{ano}^{-1}\right)$ e 4 idades de corte $(28,56,84$ e 112 dias) no capim-Tanzânia 
RODRIGUES, B.H.N. et al. Produção e composição bromatológica do capim-Tanzânia (Panicum maximum) em diferentes idades de rebrotação. PUBVET, Londrina, V. 8, N. 8, Ed. 257, Art. 1700, Abril, 2014.

encontraram variação no teor de PB de $11,45 \%$ a 5,79\% nas idades de 28 e 112 dias, respectivamente, para a dose de $400 \mathrm{~kg} \mathrm{ha}^{-1} \mathrm{ano}^{-1}$. Neste experimento, para uma dose de $\mathrm{N}$ aproximada, o valor do conteúdo de PB para 28 dias foi de $10,16 \%$, ligeiramente inferior ao daqueles autores.

Rodrigues et al. (2010) nas mesmas condições desse experimento, encontraram valor médio de PB de 13,15\% para o capim-Tanzânia aos 28 dias, irrigado com uma lâmina de 200 mm e adubado com uma dose de $\mathrm{N}$ de 300 kg $\mathrm{ha}^{-1}$.

Avaliando o capim-Mombaça, Scolforo et al. (2003), utilizando 36 dias de intervalo entre cortes e $150 \mathrm{~kg} \mathrm{ha}^{-1}$ de $\mathrm{N}$, encontraram teores médios de PB em torno de 11,39\%. Utilizando a mesma área experimental, Ruggiero (2003) aplicou as doses de 100, 200, 300 e $400 \mathrm{~kg} \mathrm{ha}^{-1}$ de $\mathrm{N}^{2} \mathrm{ano}^{-1}$ e obteve no mês de abril, respectivamente, os seguintes teores médios de PB: 11,24\%; 10,85\%; $11,94 \%$ e $11,67 \%$.

Observou-se resposta linear positiva $(P<0,05)$ dos teores de fibra em detergente neutro (FDN) com a idade de rebrotação (Figura 4), variando de $57,50 \%$ a 60,72\%, dos 7 aos 35 dias, respectivamente. Fato também observado por Magalhães et al. (2009), quando avaliaram os teores de FDN em vários cultivares de capim-elefante cortados aos 28 35, 42, 56 e 84 dias. Conforme Andrade et al. (2003), o aumento dos teores de FDN é devido a alterações fisiológicas que ocorrem com o amadurecimento das plantas forrageiras, quando o conteúdo celular diminui, como consequência da elevação das percentagens dos constituintes da parede celular.

O teor de FDN é um importante parâmetro que define a qualidade da forragem, bem como um fator que limita a capacidade ingestiva por parte dos animais. A FDN é constituída basicamente de celulose, hemicelulose e lignina (ROCHA et al., 2001) e representa a fração química da forrageira que se correlaciona mais estreitamente com o consumo voluntário dos animais, sendo que valores acima de 55 a $60 \%$ correlacionam-se de maneira negativa (VAN SOEST, 1965). No presente trabalho, os valores de FDN encontrados estiveram sempre acima do valor crítico de $55 \%$ e, portanto, o consumo voluntário das 
RODRIGUES, B.H.N. et al. Produção e composição bromatológica do capim-Tanzânia (Panicum maximum) em diferentes idades de rebrotação. PUBVET, Londrina, V. 8, N. 8, Ed. 257, Art. 1700, Abril, 2014.

forrageiras em pastejo poderia ser limitado no caso de uma pressão de pastejo alta, que reduziria a seletividade dos bovinos. Visto que o valor crítico de $60 \%$ somente foi atingido a partir do $28^{\circ}$ dia de rebrotação, admite-se que o potencial de consumo da forragem pelo ruminante poderá ser atingido até esta idade de rebrotação (ANDRADE et al., 2003).

A FDN está relacionada com a ingestão potencial de matéria seca da forragem pelos animais. O consumo de forragem pode ser predito em $\mathrm{kg} \mathrm{dia}^{-1}$, dividindo-se a capacidade de ingestão do animal $(\mathrm{kg})$ pelo enchimento do rúmen (dia) e, como a fração fibrosa do alimento é um dos fatores responsáveis pelo enchimento do rúmen, as variáveis de degradação e a taxa de passagem ruminal baseiam-se na FDN da forrageira (SOUZA et al., 2006). Além disso, de acordo com Lima et al. (2002), a FDN apresenta uma relação inversamente proporcional à densidade energética da dieta. Por isso, valores de FDN acima de $60 \%$ correlacionam-se negativamente com o consumo de forragem.

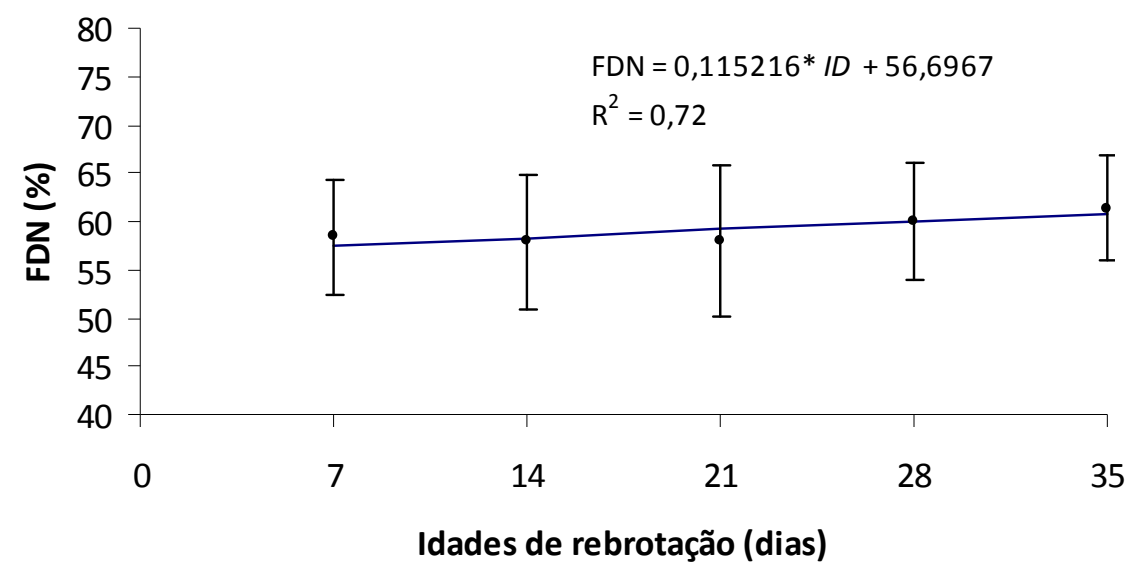

Figura 4. Valores médios observados e estimativa dos teores de fibra em detergente neutro (FDN) do Panicum maximum cv. Tanzânia em diferentes idades de rebrotação, em Parnaíba, Piauí. As barras indicam os desviospadrão. 
RODRIGUES, B.H.N. et al. Produção e composição bromatológica do capim-Tanzânia (Panicum maximum) em diferentes idades de rebrotação. PUBVET, Londrina, V. 8, N. 8, Ed. 257, Art. 1700, Abril, 2014.

França et al. (2007) trabalhando com o capim-Tanzânia sob o efeito de 3 doses de $\mathrm{N}\left(200,400\right.$ e $\left.600 \mathrm{~kg} \mathrm{ha}^{-1}\right)$ e 4 idades de corte $(28,56,84$ e 112 dias) obtiveram na dose de $400 \mathrm{~kg} \mathrm{ha}^{-1}$ teores de FDN variando de $72,80 \%$ aos 28 dias para 79,25\% aos 112 dias. Patês et al, (2008) também para o capimTanzânia aos 35 dias de rebrotação encontraram valores de FDN de 73,2; 72,$0 ; 70,2$ e 71,0\% nas doses de nitrogênio de 0,50, 100 e $150 \mathrm{mg} \mathrm{dm}{ }^{-3}$, respectivamente, próximos aos obtidos por Gerdes et al., (2000), que analisando os teores de FDN de três forrageiras (Brachiaria brizantha cv. Marandu; Setaria sphacelata e Panicum maximum cv. Tanzânia) amostradas aos 35 dias, aplicaram nitrogênio em cobertura $\left(100 \mathrm{~kg} \mathrm{ha}^{-1}\right)$ logo após o corte de rebaixamento e obtiveram concentrações médias de FDN de 68,8; 72,7; 57,9 e $62,3 \%$ para o capim-marandu; 70,$7 ; 71,5 ; 58,7$ e $62,9 \%$ para o capimsetária e 74,7; 78,8; 70,7 e 67,7\% para o capim-Tanzânia.

Todos os valores de FDN relatados acima se apresentaram superiores aos encontrados neste trabalho para o capim-Tanzânia. O baixo valor nutritivo das forrageiras tropicais é freqüentemente mencionado na literatura e está associado ao reduzido teor de PB e de minerais e ao alto conteúdo de fibra. Com o amadurecimento da planta, a produção de componentes potencialmente digeríveis - carboidratos solúveis, proteínas, minerais e outros conteúdos celulares - tende a decrescer. Ao mesmo tempo, as frações menos digeríveis, como celulose, hemicelulose protegida, cutícula e sílica e indigeríveis, como lignina, aumentam, promovendo decréscimos na digestibilidade (PATÊS et al., 2008).

Os teores de fibra em detergente ácido (FDA) apresentaram um comportamento quadrático $(P<0,05)$ (Figura 5), com valor mínimo de 33,36\% aos 19 dias e valor máximo de $36,68 \%$ aos 35 dias de rebrotação.

A tendência de aumento na FDA com o avanço da maturidade da planta ocorre, possivelmente, devido ao aumento da lignificação e à queda na relação folha/colmo, além do aumento nos constituintes de parede celular (ANDRADE et al., 2003). 
RODRIGUES, B.H.N. et al. Produção e composição bromatológica do capim-Tanzânia (Panicum maximum) em diferentes idades de rebrotação. PUBVET, Londrina, V. 8, N. 8, Ed. 257, Art. 1700, Abril, 2014.

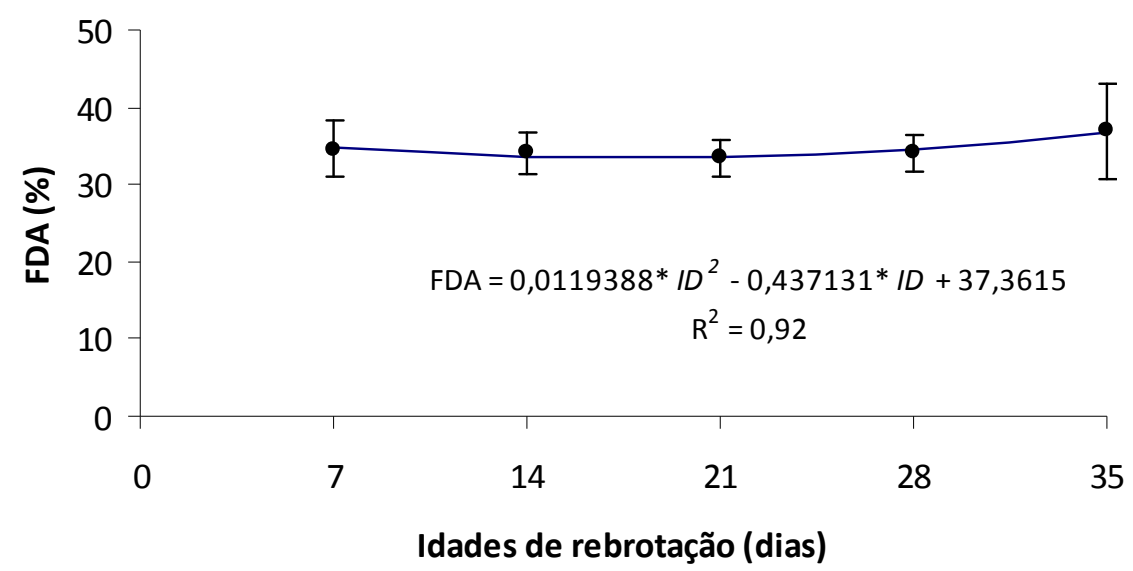

Figura 5. Valores médios observados e estimativa dos teores de fibra em detergente ácido (FDA) do Panicum maximum cv. Tanzânia em diferentes idades de rebrotação, em Parnaíba, Piauí. As barras indicam os desviospadrão.

França et al. (2007), para o capim-Tanzânia, encontraram valores de FDA variando de $41,6 \%$ aos 28 dias para $52,8 \%$ aos 112 dias de rebrotação. Freitas et al (2007), para o capim-Mombaça, encontraram valor de FDA de $40,8 \%$ aos 28 dias de rebrotação, com adubação nitrogenada de $280 \mathrm{~kg} \mathrm{ha}^{-1}$ $a_{n o}^{-1}$, resultados superiores aos encontrados neste trabalho. Segundo os autores, de um modo geral, nas plantas cujo corte é realizado mais próximo do solo, ocorre uma maior retirada de MS do colmo, que, pelo fato de apresentar maior conteúdo da parede celular, apresentam menores valores de PB, e maiores teores de FDA e FDN. Tais afirmações justificariam os maiores valores de FDA determinados naquelas pesquisas, tendo em vista que os cortes foram efetuados a $20 \mathrm{~cm}$ do solo. No entanto, neste trabalho os cortes foram efetuados mais próximos do solo $(10 \mathrm{~cm})$ e mesmo assim, os valores de FDA encontrados foram inferiores.

O teor de FDA é um fator importante quando avalia a digestibilidade de um alimento, pois à medida que aumenta os teores de FDA da forrageira, diminui a digestibilidade da MS (COSTA et al., 2007). Por sua vez, enquanto a 
RODRIGUES, B.H.N. et al. Produção e composição bromatológica do capim-Tanzânia (Panicum maximum) em diferentes idades de rebrotação. PUBVET, Londrina, V. 8, N. 8, Ed. 257, Art. 1700, Abril, 2014.

FDN é constituída basicamente de celulose, hemicelulose e lignina, a FDA é constituída principalmente de lignina e celulose, daí estar mais associada com a digestibilidade dos alimentos (ROCHA et al., 2001).

Scolforo et al. (2003) avaliando o capim-Mombaça com 36 dias de intervalo entre cortes e $150 \mathrm{~kg} \mathrm{ha}^{-1}$ de $\mathrm{N}$, encontraram teores de FDA em torno de 40\%. Por outro lado, Brâncio et al (2002), avaliando o capim-Tanzânia, encontraram teores médios de FDA de 43\%. Já Costa (2003) não observou efeitos significativos da adubação nitrogenada (150, 300 e $450 \mathrm{~kg} \mathrm{ha}^{-1}$ de N) sob os teores de FDA para o capim-Tanzânia, ficando estes, no período das águas, em torno de 38\%, resultados também superiores aos encontrados neste trabalho.

Segundo Andrade et al. (2003), com relação aos teores de FDA, forragens com valores em torno de 30\% (nível ideal para um bom consumo animal) serão consumidas em altos níveis, enquanto as com teores acima de $40 \%$, em baixos níveis. Assim, pode-se prever consumo adequado do capimTanzânia nas condições ecológicas deste experimento até a idade de 28 dias, próximo dos $35 \%$ de FDA, valor intermediário entre o nível ideal e o nível crítico.

\section{Conclusões}

Considerando a produtividade e a sua composição bromatológica, o período de descanso para o capim-Tanzânia, nas condições ecológicas dos tabuleiros costeiros do Piauí, pode variar entre 21 e 28 dias.

\section{Referências Bibliográficas}

ABRAHÃO, J.J.S. Valor nutritivo de plantas forrageiras. In: MONTEIRO, A.L.G.; MORAES, A.; CORRÊA, E.A.S. et al. Forragicultura no Paraná. Londrina: CPAF, p.93-108, 1996.

AGUIAR, R. da S.; VASQUEZ, H.M.; SILVA, J.F.C. da. Produção e composição químicobromatológica do capim-furachão (Panicum repens L.) sob adubação e diferentes idades de corte. Revista Brasileira de Zootecnia, v.29, n.2, p.325-333, 2000.

ALEXANDRINO, E.; NASCIMENTO JÚNIOR, D.; REGAZZI, A.J.; MOSQUIM, P.R.; ROCHA, F.C.; SOUSA, D.P. Produção de massa seca e vigor de rebrotação da Brachiaria brizantha cv. Marandu submetida a diferentes doses de nitrogênio e freqüências de cortes. Brazilian Journal of Veterinary Research and Animal Science, v.40, p.141-147, 2003. 
ANDRADE, A.C.; EVANGELISTA, A.R.; SIQUEIRA, G.R.; SANTANA, R.A.V. Rendimento e valor nutritivo do capim-bermuda "Coastcross" (Cynodon spp.) em diferentes idades de rebrotação. In: REUNIÃO ANUAL DA SOCIEDADE BRASILEIRA DE ZOOTECNIA, 40., 2003, Santa Maria, Anais... Viçosa: SBZ, 2003. (CD-ROM).

ANDRADE JÚNIOR, A.S. de; BASTOS, E.A.; BARROS, A.H.C.; SILVA, C.O. da; GOMES, A.A.N. Classificação climática e regionalização do semi-árido do Estado do Piauí sob cenários pluviométricos distintos. Revista Ciência Agronômica. v.36, n.2, p.143-151, 2005.

BALSALOBRE, M.A.A. Valor alimentar do capim tanzânia. Piracicaba: ESALQ, 2002. 113p. (Tese de Doutorado em Agronomia, Área de Concentração: Ciência Animal e Pastagens).

BALSALOBRE, M.A.A.; CORSI, M.; SANTOS, P.M.; VIEIRA, I.; CÁRDENAS, R.R. Composição química e fracionamento do nitrogênio e dos carboidratos do capim-Tanzânia irrigado sob três níveis de resíduo pós-pastejo. Revista Brasileira de Zootecnia, v.32, n.3, 2003.

BALSALOBRE, M.A.A.; NUSSIO, L.G.; MARTHA JÚNIOR, G.B. Controle de perdas na produção de silagem de gramíneas tropicais. In: SIMPÓSIO SOBRE MANEJO DA PASTAGEM, 2001, Piracicaba. Anais... Piracicaba: FEALQ, 2001. p.890-911.

BASTOS, E.A.; ANDRADE JÚNIOR, A.S. de; RODRIGUES, B.H.N. Boletim agrometeorológico de 2005 para o município de Parnaíba, PI. Teresina: Embrapa Meio-Norte, 2006. 38p. (Embrapa Meio-Norte, Documentos, 131).

BENEDETTI, E.; COLMANETTI, A.L.; DEMÉTRIO, R.A. Produção e composição bromatológica do capim Panicum maximum Jacq. cv. Tanzânia irrigado em solo de cerrado. Veterinária Notícias, v.7, n.2, p.123-128, 2001.

BORGES, A.L.C.C.; RABELO, L.S.; GONÇALVES, L.C. Avaliação da Brachiaria brizantha, cv. Marandu em oito idades de corte em Igarapé-MG: teores de matéria seca e relação folha: haste. In: REUNIÃO ANUAL DA SOCIEDADE BRASILEIRA DE ZOOTECNIA, 39., 2002, Recife. Anais... Recife: SBZ, 2002. (CD-ROM)

BRÂNCIO, P.A.; NASCIMENTO JÚNIOR, D.; EUCLIDES, V.P.B.; REGAZZI, A.J.; ALMEIDA, R.G.; FONSECA, D.M. Avaliação de três cultivares de Panicum maximum Jacq. sob pastejo. Composição química e digestibilidade da forragem. Revista Brasileira de Zootecnia, v.31, n.4, p.1605-1613, 2002.

CASTAGNARA D.D. Adubação nitrogenada sobre o crescimento, a produção e a qualidade de gramíneas forrageiras tropicais. Marechal Cândido Rondon: Universidade Estadual do Oeste do Paraná, 2009. 97p. (Dissertação de Mestrado em Zootecnia).

CASTRO, G.H.F.; GRAÇA, D.S.; GONÇALVES, L.C.; BORGES, I.; POSSAS, F.P.; JAYME, C.G.; NOGUEIRA, U.T.; RODRIGUEZ, N.M.; BORGES, A.L.C.; SALIBA, E.S. Degradabilidade in situ da matéria seca e proteína bruta da Brachiaria brizantha cV. Marandu em quatro diferentes idades de corte. In: REUNIÃO ANUAL DA SOCIEDADE BRASILEIRA DE ZOOTECNIA, 41., 2004, Campo Grande. Anais... Campo Grande: SBZ, 2004. (CD-ROM)

CECATO, U.; CASTRO, C.R. de C.; CANTO, M.W. do; PETERNELLI, M.; ALMEIDA JÚNIOR, J.; JOBIM, C.C.; CANO, C.C.P. Perdas de forragem em capim Tanzânia (Panicum maximum, Jacq cv. Tanzânia-1) manejado sob diferentes alturas de pastejo. Revista Brasileira de Zootecnia, Viçosa v.30, n.2, p.295-302, 2001.

CEDEÑO, J.A.G; ROCHA, G.P.; PINTO, J.C.; MUNIZ, J.A.; GOMIDE, E.M. Efeito da idade de corte na performance de três forrageiras do gênero Cynodon. Ciência e Agrotecnologia, v.27, n.2, p.462-470, 2003.

COSTA, K.A.P. Efeito da formulação $\mathbf{N}: K$ com o uso do enxofre na produção de massa seca e valor nutritivo do capim -Tanzânia irrigado. Goiânia: Universidade Federal de Goiás, 2003. 55p. (Dissertação de Mestrado em Medicina Veterinária). 
COSTA, K.A.P.; OLIVEIRA, I.P.; FAQUIN, V.; NEVES, B.P.; RODRIGUES, C.; SAMPAIO, F.M.T. Intervalo de corte na produção de massa seca e composição químico-bromatológica da Brachiaria brizantha cv. MG-5. Ciência Agrotécnica, v.31, n.4, p.1197-1202, 2007.

DANTAS NETO, J.; SILVA, F.; SANTOS, F. de A.; FURTADO, D.A.; MATOS, J. de A. Influência da precipitação e idade da planta na produção e composição química do capim-buffel. Pesquisa Agropecuária Brasileira, v.35, n.9, p.1867-1874, 2000.

EL-MEMARI NETO, A.C.; ZEOULA, L.M.; CECATO, U. Avaliação produtiva e química da Brachiaria brizantha no inverno e primavera. In: REUNIÃO ANUAL DA SOCIEDADE BRASILEIRA DE ZOOTECNIA, 39., 2002, Recife. Anais... Recife: SBZ, 2002. (CD-ROM)

EUCLIDES, V.P.B. Valor alimentício de espécies forrageiras do gênero Panicum. In: SIMPÓSIO SOBRE MANEJO DA PASTAGEM, 12., Piracicaba, 1995. Anais... Piracicaba: FEALQ, 1995. p.245-73.

EUCLIDES, V.P.B.; EUCLIDES FILHO, K.; COSTA, F.P.; FIGUEIREDO, G.R. de Desempenho de novilhos F1s Angus-Nelore em pastagens de Brachiaria decumbens submetidos a diferentes regimes alimentares. Revista Brasileira de Zootecnia, v.30, n.2, p.470-481, 2001.

FRANÇA, A.F. de S.; BORJAS, A. de L.R.; OLIVEIRA, E.R. de; SOARES, T.V.; MIYAGI, E.S.; SOUSA, V.R. de. Parâmetros nutricionais do capim-tanzânia sob doses crescentes de nitrogênio em diferentes idades de corte. Ciência Animal Brasileira, v.8, n.4, p.695-703, 2007.

FREITAS, K.R.; ROSA, B.; RUGGIERO, J.A.; NASCIMENTO, J.L. do; HEINEMAM, A.B.; MACEDO, R.F.; NAVES, M.A.T.; OLIVEIRA, I.P. de Avaliação da composição químico-bromatológica do capim mombaça (Panicum maximum Jacq,) submetido a diferentes doses de nitrogênio. Biosciense Journal, v.23, n.3, p.1-10, 2007.

GARCEZ NETO, A.F.; NASCIMENTO JUNIOR, D. do; REGAZZI, A.J.; FONSECA, D.M. da; MOSQUIM, P.R.; GOBBI, K.F. Respostas morfogênicas e estruturais de Panicum maximum cv. Mombaça sob diferentes níveis de adubação nitrogenada e alturas de corte. Revista Brasileira de Zootecnia, v.31, n.5, p.1890-1900, 2002.

GERDES, L.; WERNER, J.C.; COLOZZA, M.T.; CARVALHO, D.D. de; SCHAMMASS, E.A. Avaliação de características agronômicas e morfológicas das gramíneas forrageiras marandu, setária e Tanzânia aos 35 dias de crescimento nas estações do ano. Revista Brasileira de Zootecnia, v.29, n.4, p.947-954, 2000.

LACERDA, M da S.B.; ALVES, A.A.; OLIVEIRA, M.E. de; ROGÉRIO, M.C.P.; CARVALHO, T.B.; VERAS, V.S. Composição bromatológica e produtividade do capim-andropógon em diferentes idades de rebrota em sistema silvipastoril. Acta Scientiarum Animal Sciences, v.31, n.2, p.123-129, 2009.

LIMA; L.G.; NUSSIO; L.G.N.; GONÇALVES, J.R.S.; SIMAS, J.M.S.; PIRES, A.V.; SANTOS, F.A.P. Fontes de amido e proteína para vacas leiteiras em dietas à base de capim elefante. Scientia Agricola, v.59, n.1, p.19-27, 2002.

MAGALHÃES, J.A. Características morfogênicas e estruturais, produção de forragem e composição bromatológica de gramíneas forrageiras sob irrigação e adubação. Fortaleza: Universidade Federal do Ceará, 2010, 130p. (Tese de Doutorado em Zootecnia).

MAGALHÃES, J.A.; RODRIGUES, B.H.N.; CARNEIRO, M. do S. de; ANDRADE, A.C.; COSTA, N. de L.; PINTO, M.S.C.; MOCHEL FILHO, W.J.E. Influência da adubação nitrogenada e idade de corte sobre os teores de proteína bruta e fibra em detergente neutro de três cultivares de capim-elefante. Revista Electrónica de Veterinária, v.10, p.1-13, 2009.

MAGALHÃES, M.A. Fluxo de tecido e produção de capim-Tanzânia irrigado sob diferentes densidades de plantas e doses de nitrogênio, 2007, 76p. Dissertação (Mestrado em Zootecnia) - Universidade Federal de Viçosa, MG, 2007. 
MARTUSCELLO, J.A.; FONSECA, D.F.; NASCIMENTO JÚNIOR, D. Características morfogênicas e estruturais em plantas de capim-massai submetidas a corte e doses de nitrogênio. In: SIMPOSIUM GRASSLAND AND ECOPHISIOLOGY AND GRAZING ECOLOGY, 2., Curitiba, Anais... Curitiba, $2004-\mathrm{CD}-\mathrm{ROM}$.

MELO, F.B.; CAVALCANTE, A.C.; ANDRADE JÚNIOR, A.S.; BASTOS, E.A. Levantamento detalhado dos solos da área da Embrapa Meio-Norte/UEP de Parnaíba. Embrapa MeioNorte. 2004. 26p. (Documentos, 89).

MINSON, D.J.; WILSON, J.R. Prediction of intake as on element of forage quality. In: FAHEY Jr., G. Forage quality, evaluation, and utilization. Madison: American Society of Agronomy, 1994. p. 533-563.

NATIONAL RESEARCH COUNCIL. Nutrient requirements of beef cattle. 6.ed. Washington, D. C.: National Academy of Science, 1984. 90p.

OLIVEIRA, M.A. Características morfofisiológicas e valor nutritivo de gramíneas forrageiras do gênero Cynodon sob diferentes condições de irrigação, fotoperíodo, adubação nitrogenada e idade de rebrota. Viçosa: UFV, 2002. 142p. (Tese de Doutorado em Zootecnia).

PALIERAQUI, J.G.B.; FONTES, C.A.A.; RIBEIRO, E.G.; CÓSER, A.C.; MARTINS, C.E.; FERNANDES, A.M. Influência da irrigação sobre a disponibilidade, a composição química, a digestibilidade e o consumo dos capins mombaça e napier. Revista Brasileira de Zootecnia, v.35, n.6, p.2381-2387, 2006.

PATÊS, N.M. da S.; PIRES, A.J.V.; CARVALHO, G.G.P. de; OLIVEIRA, A.C.; FONCÊCA, M.P.; VELOSO, C.M. Produção e valor nutritivo do capim-tanzânia fertilizado com nitrogênio e fósforo. Revista Brasileira de Zootecnia, v.37, n.11, p.1934-1939, 2008.

PENA, K. da S. Características morfogênicas e estruturais e acúmulo de forragem do capim-Tanzânia submetido a intensidades e frequências de corte, Viçosa: Universidade Federal de Viçosa, 2007. 95p. (Dissertação de Mestrado em Zootecnia).

RIBEIRO, E.G. Influência da irrigação na produção de matéria seca e valor nutritivo das forrageiras Panicum maximum Jacq. e Penisetum purpureum, Schum. e no ganho de peso de novilhos europeu-zebu. Campos dos Goitacazes: Universidade Estadual do Norte Fluminense, 2004. 89p. (Tese de Doutorado em Produção Animal).

RIBEIRO, E.G.; FONTES, C.A.A.; MARTINS, C.E.; CÓSER, A.C. PALIERQUI, J.G. B. Produção de matéria seca total, foliar e composição química da folha dos capins elefante cv. Napier (Pennisetum purpureum Schum.) e Panicum maximum Jacq. cv. Mombaça, sob irrigação. In: REUNIÃO DA SOCIEDADE BRASILEIRA DE ZOOTECNIA, 41., 2004, Campo Grande. Anais... Campo Grande: SBZ, 2004. (CD-ROM).

ROCHA, G.P.; EVANGELISTA, A.R.; PAIVA, P.C. de; FREITAS, R.T.F. de; SOUZA, A.F. de; GARCIA, R. Digestibilidade e fração fibrosa de três gramíneas do gênero Cynodon. Ciências Agrotécnicas, v.25, n.2, p.396-407, 2001.

RODRIGUES, A.L.P.; SAMPAIO, I.B.M.; CARNEIRO, J.C.; TOMICH, T.R.; MARTINS, R.G.R. Degradabilidade in situ da matéria seca de forrageiras tropicais obtidas em diferentes épocas de corte. Arquivo Brasileiro de Medicina Veterinária e Zootecnia, v.56, n.5, p.658-664, 2004.

RODRIGUES, B.H.N.; ANDRADE, A.C.; MAGALHÃES, J.A.; COSTA, N. de L.; BEZERRA, E.E.A. Determinação do teor de proteína bruta de Panicum maximum cV. Tanzânia, sob diferentes níveis de irrigação e adubação nitrogenada. Pubvet, v.4, n.26, ed.131, Art\#888, 2010. (www.pubvet.com.br) 
RODRIGUES, B.H.N.; MAGALHÃES, J.A.; LOPES, E.A. Irrigação e adubação nitrogenada em três gramíneas forrageiras no Meio-Norte do Brasil. Revista Ciência Agronômica, v.36, n.3, p.274-278, 2005.

RODRIGUES, B.H.N.; MAGALHÃES, J.A.; CAVALCANTE, R.F.; BARROS, W.S. Efeito da idade de corte sobre o rendimento forrageiro do capim-Tanzânia irrigado nos Tabuleiros Litorâneos do Piauí. Revista Científica de Produção Animal, v.8, n.2, p.21-27, 2006.

RUGGIERO, J. Avaliação de diferentes lâminas de água e de doses de nitrogênio na produção de matéria seca e composição bromatológica do capim Mombaça. Goiânia: Universidade Federal de Goiás, 2003. 62p. (Dissertação de Mestrado em Agronomia).

SCOLFORO, L.; VASQUEZ, H.M.; SILVA, J.F.C.; DETMANN, E.; CLIPES, R.C.; SOUZA, P.M.; HADDADE, I.R.; PERES, A.A.C. Desempenho de novilhas em pastagens de "Pennisetum purpureum" Schum. cv. napier e "Panicum maximum" Jacq. cv. Mombaça, com acesso a banco de proteína de "Stylosanthes guianensis" cv. Mineirão. In: REUNIÃO ANUAL DA SOCIEDADE BRASILEIRA DE ZOOTECNIA, 39., 2003, Santa Maria. Anais... Santa Maria: SBZ, 2003. (CDROM)

SILVA, D.J.; QUEIROZ, A.C. Análises de alimentos: métodos químicos e biológicos. $3^{a}$ ed. Viçosa. Imprensa Universitária. UFV, 2002. 235p.

SILVA, M.W.R. da. Características estruturais, produtivas e bromatológicas das gramíneas tifton-85, marandu e tanzânia submetidas à irrigação. Itapetinga: UESB, 2009. 54p. (Dissertação de Mestrado em Zootecnia, Área de Concentração em Produção de Ruminantes).

SOUZA, C.G. de; SANTOS, M.V.F. dos; SILVA, M. da C.; CUNHA, M.V. da; LIRA, M. de A. Medidas qualitativas de cultivares de Panicum maximum Jacq. submetidas a adubação nitrogenada. Revista Caatinga, v.19, n.4, p.333-338, 2006.

SOUZA, G.B; NOGUEIRA, A.R.A.; SUMI, L.M. Método alternativo para a determinação de fibra em detergente neutro e detergente ácido. São Carlos. Embrapa Pecuária Sudeste, 1999. 21p.

TINOCO, A.F. da F.; DINIZ, M.C.N. M.; da SILVA, J.G.M.; MEDEIROS, H.R.; RANGEL, A.H. do N. Características morfológicas e desenvolvimento do capim tanzânia submetido a diferentes alturas de corte, sob irrigação. Revista Verde, v.3, n.4, p.58-63, 2008.

VAN SOEST, P.J. Symposium on factors influencing the voluntary intake of herbage by ruminants: voluntary intake relation to chemical composition and digestibility. Journal of Animal Science, v.24, n.3, p.834-844, 1965.

VAN SOEST, P.J. Nutritional ecology of the ruminant. Ithaca, New York: Cornell, 1994. 476p.

VERDECIA, D.M.; RAMIREZ, J.L.; LEONARD, I.; PASCUAL, Y.; LÓPEZ, Y. Rendimiento y componentes del valor nutritivo del Panicum maximum cv. Tanzânia. Revista Electrónica de Veterinaria, v.9, n.5, p.1-9, 2008. 